\begin{abstract}
Iranica
Abstracta Iranica Revue bibliographique pour le domaine irano-aryen

Volume 40-41 | 2019

Comptes rendus des publications de 2017-2018
\end{abstract}

\title{
Thomas S. Flynn. The western Christian presence in the Russias and qājār Persia, c. 1760- c. 1870
}

\section{Alisa Shablovskaia}

\section{(2) OpenEdition}

1 Journals

\section{Édition électronique}

URL : http://journals.openedition.org/abstractairanica/50313

DOI : 10.4000/abstractairanica.50313

ISBN : 1961-960X

ISSN : 1961-960X

Éditeur :

CNRS (UMR 7528 Mondes iraniens et indiens), Éditions de l'IFRI

Référence électronique

Alisa Shablovskaia, «Thomas S. Flynn. The western Christian presence in the Russias and qäjär Persia, c. 1760- c. $1870 »$, Abstracta Iranica [En ligne], Volume 40-41 | 2019, document 1, mis en ligne le 30 décembre 2019, consulté le 24 avril 2021. URL : http://journals.openedition.org/abstractairanica/ 50313 ; DOI : https://doi.org/10.4000/abstractairanica.50313

Ce document a été généré automatiquement le 24 avril 2021

Tous droits réservés 


\title{
Thomas S. Flynn. The western Christian presence in the Russias and qājār Persia, c. 1760- c. 1870
}

\author{
Alisa Shablovskaia
}

\section{RÉFÉRENCE}

Thomas S. Flynn. The western Christian presence in the Russias and qājār Persia, c. 1760- c.

1870. Leiden, Boston (Masse.): Brill, 2017, 944 p.

1 Le christianisme apparaît sur le territoire de l'Iran actuel à l'époque des Parthes quand le rite syriaque oriental (chaldéen) commença à se répandre - le processus traditionnellement associé aux activités de prédication de Saint Thomas (m. 72). La liturgie araméenne étant établie à l'ère sassanide, au moment de la conquête musulmane de l'Empire iranien la foi chrétienne y était déjà largement présente. Durant la période médiévale, les activités missionnaires européennes connurent leur essor en Iran au XIII ${ }^{e}$ siècle et durant le XVII ${ }^{e}$ siècle certains missionnaires européens purent accéder à de prestigieux postes de conseillers dans la cour safavide. La fin du règne safavide (1736) et plusieurs décennies de luttes politiques tumultueuses qui s'en suivirent conduisirent à un déclin drastique de la présence missionnaire en Iran, celleci de nouveau tangible à partir des années 1750 .

2 Cet ouvrage encyclopédique de Flynn traite l'étape "moderne» de l'histoire missionnaire qui, dans le contexte iranien, correspond à la période entre la consolidation des élites qajar jusqu'à la modernisation massive de l'état qajar sous Naser al-Din Shah (r. 1848-96). Divisé en douze chapitres, le récit très détaillé de Flynn commence par une introduction assez généraliste, stipulant le caractère descriptif de l'ouvrage qui, selon son auteur, n'a pas pour vocation de proposer une problématique concrète, mais de fournir un aperçu dense et riche en données factuelles. Dans le cadre de cette approche énoncée, l'auteur procède ensuite à l'étude de la présence catholique 
et protestante en Iran et à Bagdad au tournant du XIX ${ }^{e}$ siècle (Chapitres 2-3), se penche ensuite sur les activités missionnaires jésuites et protestants principalement en Empire russe (Chapitres 4-6), examine la mission presbytérienne américaine et la mission lazariste française à l'est de l'Iran (Chapitres 7-8) et finit son récit avec deux chapitres consacrés aux contacts des missionnaires européens avec les juifs iraniens (Chapitres 9-10). La variété des sources mises à contribution est impressionnante : l'auteur utilise des sources inédites conservées en Écosse, Belgique, Suisse, Angleterre, États-Unis, Italie, France, Vatican et Allemagne aussi bien dans les centres d'archives publiques que dans les collections privées. Outre les trajectoires personnelles des missionnaires et l'environnement périlleux des rencontres interculturelles, Flynn met en exergue les tensions à l'intérieur de leurs organisations, dues souvent aux besoins financiers et aux impératifs politiques, avec en filigrane l'histoire sociopolitique des sociétés d'accueil notamment, la hausse de l'influence anglo-russe en Iran et la conquête tsariste du Caucase.

Cependant, malgré de nombreux passages dédiés aux spécificités des sociétés d'accueil au fil du texte, la perspective historiographique de l'ouvrage peut être qualifiée d'eurocentrique: les ordres missionnaires chrétiens sont approchés comme les institutions essentiellement philanthropiques (p. 676) et la complexité des structures sociales des sociétés d'accueil n'apparaissent qu'au second plan. La moitié du récit étant située dans le contexte impérial russe, l'absence des sources et de la littérature secondaire en langue russe dans la bibliographie laisse le lecteur perplexe. Enfin, l'organisation de l'ouvrage est marquée par des chevauchements des aires géographiques non justifiés, la logique de l'association «Russie-Iran» n'étant pas claire.

4 L'ouvrage de Flynn restera, indubitablement, pendant des décennies à venir un travail fondamental sur l'histoire missionnaire qui pourra être utile à tous les chercheurs en études russes et iraniennes, ainsi que pour ceux qui s'intéressent à l'histoire du christianisme au Moyen-Orient.

\section{AUTEURS}

\section{ALISA SHABLOVSKAIA}

Doctorante Sorbonne Nouvelle, Mondes iranien et indien, Paris 